http://dx.doi.org/10.12795/PH.1990.v05.i01.23

\title{
Eugenio Cambaceres: el perfeccionamiento de un escritor
}

Rita Gnutzmann

Es ya un clisé entre los críticos alabar la tercera novela de Cambaceres (18431889) y pasar muy rápido por encima de las primeras dos, si es que las mencionan. No quiero decir que Potpourri (1882) y Música sentimental (1884), ambàs con el subtítulo Silbidos de un vago, tengan el mismo valor que Sin rumbo $(1885)^{1}$, pero pueden servir precisamente para mostrar el camino tomado por el autor, su innegable aprendizaje y la evolución de elementos presentes ya en los dos primeros relatos.

Recuerdo brevemente los argumentos de estos, ya que son poco conocidos y prácticamente inaccesibles. Potpourri, más que una novela con trama desarrollada, es ante todo una farsa de la alta sociedad porteña. En segundo lugar cuenta la infidelidad de un joven matrimonio, Juan y María, practicada por ambos, aunque extrañamente (o como sería normal en aquella sociedad) sólo se critica a la mujer por su inconstancia y búsqueda de aventuras. El problema se soluciona felizmente comprando la renuncia del amante de María.

Música sentimental desarrolla un argumento desde el comienzo hasta el final. Relata las experiencias de un rastacuero porteño en París y en los casinos de Mónaco. En un duelo por infidelidad matrimonial, en el que pierde la vida el Conde engañado, Pablo es herido y la sífilis que sufre sin saberlo no permite su curación. Loulou, la prostituta redimida por el amor, lo cuidará abnegadamente hasta su muerte. Es obvio que la novela está inspirada en el tema de María Magdalena y más directamente en La dama de las camelias (1848) de Dumas, hijo. Es fácil imaginarse a Cambaceres, aficionado empedernido al teatro, presenciando una de las adaptaciones dramáticas de la misma obra, durante una de sus estancias en París, donde, a partir de 1852, tales representaciones pertenecían al repertorio más exitoso. Es posible que, por este modelo directo,

\footnotetext{
${ }^{1}$ Se cita según las ediciones mencionadas en la bibliografía.
} 
muchas escenas pequen de sentimentales y melodramáticas. Pero cuando Cambaceres escribe su novela, ya domina el naturalismo al que el autor se siente atraído y por ello el carácter de Loulou sufre una evolución que no conoce Marguerite Gautier².

Lo que llama la atención en las dos primeras novelas (si se quiere incluir Potpourri en este género, tal como reza el subtítulo: «novela argentina»), es la presencia de un narrador-comentarista en primera persona, en boca (o pluma) del cual está puesto todo el relato. Este personaje da el tono, pone los acentos y no permite que los personajes se expresen libremente. Fijémonos en este personaje que prácticamente es idéntico en ambos textos, incluso se sospecha que es el mismo «Fabio» que se pasa de uno a otros ${ }^{3}$. Se presenta en Potpourri con un bostezo:

«Vivo de mis rentas y nada tengo que hacer. Echo los ojos para matar el tiempo y escribo... No quiero ni puedo hacer nada serio. El más pequeño esfuerzo intelectual me postra. Vivo por vivir, o mejor: vegeto...» (p. 14).

Estas frases se han hecho famosas y prácticamente todos los críticos las aprovechan para usarlas como definición del prototipo del 80 y para definir al propio Cambaceres (cf. Jitrik, Viñas, Giménez Pastor en su edición de Música sentimental y Cymerman en la suya de En la sangre). Se prestan a la comparación con las «Dos palabras del autor» que Cambaceres escribió para la tercera edición de la novela en 1883 en París, tras haber levantado «tal polvareda, tanto alboroto y tanta grita» (p. 6). En efecto, el mismo Cambaceres se presenta como «flaneur» y «sin rumbo» («bola de manija»). Pretende que se puso a escribir sin ninguna seriedad; «entre un bostezo a dos carrillos y un tarro de caporal» fabricó ese «atajo de vaciedades». Hasta aquí va todo bien: Fabio (sólo una vez y muy tarde, en la página 170 se da su nombre) se parece al propio autor. Pero sigamos; cambia el tono y realmente hace lo que no pretendía hacer: se toma en serio su oficio y se justifica:

«pienso con los sectarios de la escuela realista (léase naturalista) que la exhibición sencilla de las lacras que corrompe el organismo social es el reactivo más enérgico que contra ella pueda emplearse... he copiado del natural, usando de mi perfecto derecho» (p. 7).

\footnotetext{
${ }^{2}$ En Potpourri el narrador, para referirse a las mujeres venales, cita a «todas las Gauthier» (sic) y de paso menciona al galán (Armand) Duval, p. 198.

${ }^{3}$ Existe otro personaje que aparece en ambos relatos: don Pepe, ex amante de María en Potpourri, se presenta como Cónsul en Mónaco en Música sentimental. La última frase de Potpourri: «Suite au prochain numéro» enlaza directamente con Música sentimental que constituiría el «capítulo siguiente». Además el tema del adulterio se repite en las tres novelas y el capítulo 5 de Música sentimental es otra versión del capítulo 15 de Potpourri; a su vez la irrupción del marido engañado en el palco en Sin rumbo (cpt. 20) es una variación de la misma situación (de a tres) en Música sentimental (cpt. 12); el intento de conciliación de las partes mediante un amigo en Sin rumbo (cpt. 22) repite con la misma mentira pero con diferente resultado el del capt. 16 de Música sentimental. Por último, la escena en la fonda de la estación en Potpourri (pp. $106 \mathrm{ss}$.) se parece en cuanto al tema a la noche que pasa Andrés en un hotelucho de pueblo (Sin rumbo, cpt. 27), aunque en el primer caso el tono es humorístico y en el segundo se acerca al naturalismo.
} 
No veo cómo se puede confundir al cínico Fabio con el autor, quien además a continuación muestra su seriedad al citar una larga lista de autores, desde Aristófanes a Zola, quienes expusieron como él los defectos de la sociedad y «desollaron al prójimo». Alterna constantemente entre un tono humorístico-inofensivo y otro seriocrítico: acusa a los mismos lectores que alborotan ahora de haber «colaborado» por ofrecer ciertos vicios. A pesar de que afirme que sólo quería hacer reír, se contradice (a no ser que piense decir que con la risa se educa, idea rabelaisiana), porque poco antes mencionaba que sabía que minaría «los cimientos de un edificio» (la sociedad) 4 .

Existen otros indicios, como la insistencia en retratar personajes «sin rumbo» desde Potpourri $i^{5}$, pero baste esto para que no se confundan autor y narrador. Ya se sabe que el narrador es un personaje que se aburre y al que le pesa el mínimo esfuerzo intelectual. La culpa, al parecer, la tiene la educación que sufrió en su infancia: sentía auténtica pasión por el teatro, pero el desprecio social por el artista impidió que llegara a ser un buen actor y los padres le obligan a elegir la carrera de abogado. En vez de estudiar derrocha su dinero en teatros y salones y pronto cierra su despacho. Desde entonces, dominado por el spleen, se dedica a la vida ligera -tiene más de cuarenta años en la actualidad-, aunque evidentemente saca provecho de ella, observando a la sociedad y fustigando sus vicios. El protagonista de la ligera acción, Juan, resume el carácter de Fabio de esta forma:

«la detestable escuela moral en que te habías educado y cuya funesta influencia no has sido hombre capaz de sacudir... De ahí tus desconfianzas y tus dudas, de ahí tus cavilaciones, tu egoísmo, tu spleen que raya en monomanía, la falta de fe en tus semejantes, el desesperante aislamiento en que vives encerrado, de ahí, en una palabra, tu absoluto pesimismo, cuya primera víctima eres tú» (p. 127).

Prácticamente tenemos un anticipo de lo que será Andrés de Sin rumbo. Pero en realidad existe una discrepancia con la imagen de solterón satisfecho que ofrece en la página 212: lector aficionado a Voltaire, fumador en pipa que se pasa el día en zapatillas, no pide más que un buen amigo, una botella de anisette y seis barajas. Antes de un carácter trágico encontramos una pose, una postura cínica que conduce en Potpourri a criticar a la sociedad como colectivo y en Música sentimental a un tipo concreto de esta, el joven rastacuero que malogra su herencia y su vida en Francia ${ }^{6}$. Toda la acción de las

${ }^{4}$ A. Tcachuk no admite el propósito moralizador, sino que cree en el «placer malsano» del «espíritu enfermo» de Cambaceres y su «resentimiento» (p. 58).

${ }^{5} \mathrm{La}$ idea del hombre moderno «sin rumbo» se encuentra en el título de la tercera novela, pero también en la carta a la Amorini («bola sin manijo») y en el capítulo 19 y 25. Ya está presente en Potpourri: «bola sin manijo», «cambiar de rumbos» (pp. 5,6) e igualmente en Música sentimental: Pablo se encuentra «sin rumbo» en Francia: «Ando literalmente boleado... No sé qué rumbo agarrar» (p. 34 ss.). Asimismo la prostituta Blanca se encuentra «sin rumbo». No queda mucho del tan mencionado optimismo de los del 80; parece que Cambaceres se dio perfectamente cuenta del carácter de transición de su época y reconocía la inseguridad de los hombres.

${ }^{6}$ Véase el presagio del narrador de Música sentimental de lo que será la vida de Pablo, deducido seguramente de su propia existencia: «El espíritu se embota, el corazón se gasta, el cuerpo se cansa, un negro desencanto se apodera de nosotros... llega hasta traducirse en el desprecio más profundo por todo lo que es humano, en el más inaguantable hastío de la existencia». 
dos primeras novelas es filtrada a través de la voz de este personaje, con el resultado de que Potpourri parece más bien una farsa teatral (recuerda al «Manager of the Performance» de Vanity Fair de Thackeray quien levanta el telón al comienzo de la obra). En Música sentimental, igualmente ocupa el primer plano y el drama (en buena parte melodrama) queda relegado al fondo, a lo cual contribuye, además, la obstinación del personaje en explicar a los protagonistas sus propios sentimientos y comportamientos, como si fuesen menores de edad o de razón.

En Sin rumbo, el autor felizmente ha abandonado a este intruso: la acción se presenta directamente y el narrador es apenas visible. A menudo incluso se confunden la voz del personaje y la de aquel en un adjetivo que constituye un comentario, por ejemplo, cuando habla de la «odiosa excepción» del portero del Teatro Colón, quien permite que Andrés entre: «odiosa», evidentemente desde el punto de vista de los aficionados a los que se prohibe la entrada (p. 81).

El progreso de Sin rumbo sobre las anteriores novelas se observa en el capítulo 21; en él, Andrés busca en el Café de París a amigos suyos para arreglar el asunto del duelo. El anónimo antiguo compañero de colegio desempeña el mismo papel de intermediario ante el marido ofendido que el narrador en Música sentimental, sin que su función vaya más allá del capítulo 22 (aparte de que lleva a otro resultado: evita el duelo).

Otro adelanto conseguido con la escisión del narrador-comentarista es el abandono de los apóstrofes al lector, innumerables en Potpourri y menos frecuentes en Música sentimental. Desde el comienzo de la primera, el narrador se dirige confidencialmente a su público: «Ya saben Vds., pues, a que atenerse». Probablemente influye en este relato lo que insistentemente subrayan Viñas y Jitrik: el escritor del 80 escribe para sus iguales. De las cartas de Cambaceres, publicadas por Cymerman (1971), sobre todo la tercera, se deduce la necesidad de sentirse comprendido y de compartir «ab-so-lu-ta-men-te» las actitudes vitales con otros escritores, como Cané. Pero en realidad, -el último lo demostró en su reseña condenatoria de $\operatorname{Sin} r u m b o^{7}$ - no existía tal coincidencia de gustos y actitudes con el público oficial, sus colegas. El narrador invita constantemente a su lector ${ }^{8}$ a opinar sobre los sucesos y enjuiciarlos. En Música sentimental, esta actitud de compadre desaparece y sólo está presente en el colofón acerca de la vida de Loulou: « ¿Y Loulou? Se les ocurre, acaso preguntar...» (p. 207). Huelga decir que estas confianzas con el lector están ausentes en Sin rumbo, y el narrador sólo se hace presente muy discretamente en un comentario generalizador como, por ejemplo, el que abre el capítulo 19 sobre la «naturaleza de ciertos temperamentos de mujer».

La obstinada presencia del narrador llega a hacerse odiosa al comienzo y al final de muchos capítulos de las dos obras primerizas, dejando constancia de la inmadurez del autor. El capítulo 4 de Potpourri comienza con la siguiente presentación: «Tengo el gusto de presentar a Vds. a don Juan José Taniete...»; el séptimo, con la frase: «Volvamos a mi viaje y a mi compañero» (al que hemos perdido de vista en el capítulo

${ }^{7}$ Miguel Cané, «A propósito de Sin rumbo, Su-América, n² 408, 30 de Octubre 1885; el texto es más accesible en la edición de Teresita Frugoni de Fritzsche de Sin rumbo (1980).

${ }^{8}$ En realidad se puede explicar también como actitud del director de marionetas que se dirige a su público, actitud compartida por Thackeray. 
3); el capítulo 8 termina de esta forma: «con lo que cayó el telón...»; el noveno: «ofrezco a ustedes el siguiente par de escenas...». En Música sentimental, los comienzos y finales de capítulo han mejorado considerablemente y, sólo por excepción, encontramos uno como: «Al otro, ahora» (cpt. 10) ${ }^{9}$. El paso de un capítulo a otro queda asimismo dudoso, como prueba el final del quinto y comienzo del sexto de Potpourri, que retoma la palabra «republicano» para presentar una comedia en cuatro actos a continuación.

También en la estructura se observa la evolución del autor. En el párrafo anterior ya se han señalado los problemáticos cierres y transiciones de las dos primeras obras. En Sin rumbo, tal vez todavía se podría citar la transición del capítulo 27 al 28 . El primero de ellos termina con la constatación de que Andrés se duerme. Comienza el siguiente con la pesadilla que sufre a continuación; sin embargo, la separación se justifica por la temática nueva e incluso insólita en su tiempo, verdadero anticipo del surrealismo.

Potpourri se divide en 27 capítulos (hay un error de numeración en la edición de Minerva) de los que sólo la mitad desarrolla la acción, mientras que la otra mitad (que predomina en la primera parte) se pierde en comentarios y digresiones. La extensión de los capítulos varía entre dos (cpt. 2,16) y veintidós páginas (cpt. 3). Música sentimental está dividida, a su vez, en 34 capítulos; según el mismo recuento, el contraste es parecido: una página para los capítulos $3,7,8,9$ y 30 y veintiséis páginas para el más largo (cpt. 5). Sin rumbo es la única novela de Cambaceres dividida en dos partes; la diferencia de extensión entre los capítulos es menor: de una página a ocho. Aunque las dos partes discrepan considerablemente con respecto al número de capítulos (32 y 13), George D. Schade ha comprobado que existe una estructura perfecta, siempre que la enfoquemos desde el aspecto espacial: 13 capítulos en el campo, otros 13 a continuación en la ciudad y 6 de nuevo en el campo; los 13 capítulos de la segunda parte tienen lugar asimismo en el campo (1978:18).

También el contenido de los capítulos se presta a la comparación. En las dos primeras novelas, el narrador hincha a menudo artificialmente los capítulos con comentarios políticos y pseudofilosóficos, para hacer gala de su experiencia mundana. En Sin rumbo hay sólo un capítulo, el 34, que abandona del todo la acción para demorarse en las cavilaciones de Andrés acerca del destino de la mujer (y el futuro de su hija). Pero existe una diferencia como del día a la noche con los textos anteriores: gran parte de las reflexiones de Andrés se presentan en estilo indirecto libre (preguntas, exclamaciones, frases sincopadas) que permiten ver las dudas en su dinámico desarrollo.

Si nos planteamos la cuestión de hasta qué punto son imprescindibles los capítulos llegamos a la misma conclusión: el evidente perfeccionamiento en el arte de narrar de Cambaceres. Dejo de lado a Potpourri, ya que es obvio que gran número de los capítulos son digresiones. Pero también en Música sentimental se encuentran varios capítulos cuya necesidad es dudosa: el capítulo 3 simplemente explica que el narrador envía una

${ }^{9}$ Hay que reconocer el arte de Cambaceres para hacer al lector reflexionar sobre los cambios efectuados a lo largo de la novela al presentar prácticamente la misma escena en el segundo y en el penúltimo capítulo: en ambos Pablo llega a París y el narrador le recomienda alquilar un apartamento; en el primer caso es para instalarse en la nueva vida, en el segundo, como paso previo a la tumba. 
nota a Loulou; el capítulo 7 no hace más que constatar que cesan las visitas de Pablo al narrador; la descripción paisajística del capítulo 9 sirve de enlace y evita el cambio abrupto de espacio; el episodio del capítulo 20 acerca del Cónsul borracho es absolutamente superfluo y, ¿para qué sirve el ataque de lujuria de Fabio en el capítulo 14? A pesar de que persistan «escenas costumbristas» en Sin rumbo, por ejemplo, la esquila en el primer capítulo, la capa y hierra en el 11 y la tormenta en el 37, no se las puede calificar de prescindibles: no sólo explicitan el carácter de Andrés sino también el enfrentamiento con el «chino» Contreras, que finalmente lleva a la destrucción del mundo ficticio.

También deben interesar al crítico los logros del escritor con respecto a la caracterización de los personajes, si bien es cierto que en nuestros días la fidelidad psicológica es un valor muy discutido y no sólo desde el «nouveau roman» francés; ya bastante antes Macedonio Fernández en su teoría de la «novelística consciente» propuso suprimir «la narrativa, la descripción, los famosos caracteres...» (Museo de la novela de la Eterna) y los «psiquismos y borrosidades asociativas» ${ }^{10}$.

Cambaceres, como es lógico dada la época en la que escribe, aún intenta crear caracteres congruentes y evolutivos y mostrar todos los entresijos de sus motivaciones. Ello es cierto a pesar de que sufre sin duda la influencia del naturalismo, que en principio le hace reducir las motivaciones a razones de educación y medio ambiente.

En Potpourri la psicología brilla por su ausencia. Si al comienzo Juan se nos presenta «locamente» enamorado de su novia, a partir del capítulo 15 es un don Juan desvergonzado. Esta ruptura realmente no importa, ya que se trata más bien de una farsa o comedia de tipos como se dijo antes. Los nombres de los personajes subrayan este hecho: el de Juan se repite dos veces (el marido y el criado del narrador); el de Pepe otras dos veces (el amante de María y el marido de la amiga de la madre) al que se añade el de Pepa (la amiga de la madre) y el de María que no la distingue de la mayoría de las mujeres, bien sean reales o bien ficticias (comenzando por la María de La cautiva de su compatriota Echeverría). Con estos nombres prácticamente ya hemos agotado los recursos onomásticos; el único que se diferencia hasta cierto punto es el narrador «Fabio». Sin especial arte se presenta algún pensamiento de éste en notas a pie de página (pp. 165 ss.). Pero, para hacer justicia al autor, hay que reconocer el mérito del final del capítulo 12. Tras una escena presentada con los recursos del teatro, entre María y Fabio, éste se queda reflexionando sobre las mujeres («frailty, thy name is woman») durante cuatro largos párrafos (largos para lo que suelen ser los de Cambaceres), como si de un verdadero monólogo interior se tratara: primera persona del singular, exclamaciones, preguntas, lenguaje coloquial..., aunque luego se cierra con la constatación: «Fueron estas las ideas que me asaltaron» (p. 136).

${ }^{10} \mathrm{Cf}$. El rechazo de Jorge Enrique Adoum en su novela Entre Marx y una mujer desnuda: «Y hasta cuando vamos a estar describiendo (los personajes)..., curiosidad malsana, pereza mental a que nos acostumbró la novela tradicional, exigiéndole a la literatura que nos dé el retrato terminado en lugar de ir formando el rostro» (p. 120). El único en tener un carácter complejo y sufrir cierta evolución en Sin rumbo es Andrés; todos los demás representan tipos, hecho explicitado ya en sus nombres: Donata (donar), Amorini (amorío), Gorrini (gorro, comudo), Regino (regio), Contreras (contra)... 
Pasemos por alto los cambios psicológicos que sufren Pablo y Loulou en Música sentimental, ambos bajo el clisé de la redención por el amor, y recordemos lo que se dijo más arriba sobre la obstinación del narrador en explicarles a los dos sus propios sentimientos. Me interesa aquí mostrar cómo el autor soluciona técnicamente la presentación de procesos mentales de los personajes. Existen dos escenas comparables en Música sentimental (cpt. 23) y Sin rumbo (cpt. 28); en ambos casos se trata de la presentación de una visión: el delirio de Pablo durante su enfermedad y la pesadilla de Andrés durante su viaje en coche. El delirio de Pablo se introduce mediante la voz del narrador: «Los hechos que acababan de labrar un hondo surco en la existencia de aquel hombre... se agolpaban en tropel a su cabeza». En vez de ceder la voz al propio Pablo, sigue la descripción del narrador:

«Acariciaba el espléndido cuerpo desnudo de la adúltera, cubría de besos sus senos palpitantes, chupaba la fresca pulpa de sus labios, aspiraba el perfume...».

Qué excelente ocasión perdida para hacer revivir las sensaciones de Pablo (en la página 163 se dice que se trata de las palabras de él «soltadas en retahíla»), pero no: como de costumbre el narrador se tiene que poner en primer lugar. Sin embargo, incluso en esta escena fallida, se nota claramente el dinamismo del arte de narrar de Cambaceres en la yuxtaposición de frases breves sin cópula, introducidas por verbos: «acariciaba..., cubría..., chupaba..., aspiraba...». No sorprende que la reproducción de estados anímicos del propio narrador esté mucho más lograda. En el capítulo 15 tenemos prácticamente un monólogo interior de más de una página ( «Pablo no había sido nunca mi amigo» hasta el final) en el que Fabio «Pleitea circunstancias atenuantes» para su ataque de lujuria hacia Loulou.

Dijimos que el episodio comparable con el delirio de Pablo se sitúa en el capítulo 28 de Sin rumbo, que reproduce la pesadilla de Andrés; desfilan imágenes rápidas en las que su imaginario hijo se transforma a través de constantes metamorfosis monstruosas. Es uno de los primeros intentos (si no el primero) de expresar estados oníricos en la literatura hispanoamericana ${ }^{11}$. Las frases breves, sincopadas, sin verbo, la acumulación de sensaciones e imágenes, los puntos suspensivos, exclamaciones y repeticiones sugieren la adaptación al punto de vista del personaje, aunque el narrador no desaparezca del todo.

Por último, algunas observaciones acerca del lenguaje y el estilo. El lenguaje de Potpourri recuerda sobre todo el de la charla, del tipo que Mansilla usa para sus Causeries del jueves ${ }^{12}$. Utiliza el habla coloquial que mezcla las típicas expresiones criollas con extranjerismos, ante todo del francés. Este estilo era típico de la alta

${ }^{11}$ Medio siglo más tarde encontramos escenas parecidas en El Señor Presidente de Asturias: el ojo de vidrio que persigue a Genaro Rojas, el falo enorme que se arrastra por el suelo de la habitación de Niña Fedina, el sueño de Camila poblado de caramelos y pelotas... Como dice Asturias en la misma novela: «Entre la realidad y el sueño la diferencia es puramente mecánica» (p. 415).

${ }^{12} \mathrm{Cf}$. Viñas y Jitrik; cf. Mansilla: «Hablaremos, lector amigo, inter nos, como si conversáramos en viaje, sin plan, ni método, de lo que hemos visto u oído» (1963: 341). 
burguesía y del «clubman» y aunque Lucio V. López lo ridiculice, él mismo es víctima de los galicismos de moda en La gran aldea:

«No era chic hablar español en el gran mundo; era necesario salpicar la conversación con algunas palabras inglesas, y muchas francesas, tratando de pronunciarlas con el mayor cuidado, para acreditar raza de gentilhombre» (1974: $121 \mathrm{s.}$ ).

Anotemos como circunstancia atenuante el hecho de que Cambaceres era hijo de padre francés y pasaba mucho tiempo en París ${ }^{13}$. Potpourri peca por la abundancia de frases enteras en francés y tampoco faltan ejemplos del latín, italiano e incluso del inglés, aunque es obvio su uso irónico al referirse al «high-life». Esta acumulación en cierto modo pretenciosa choca con el lenguaje típicamente argentino, lleno de refranes, coloquialismos e incluso vulgarismos («bochinche, chingado, en la perra vida, anduvimos la seca y la meca», a Loulou en Música sentimental se llama «horizontal de marca», p. 208). Con fines humorísticos (según Viñas, por desprecio hacia el inferior) el autor ofrece muestras del lenguaje del criado gallego Taniete: «si nu es más que esu, nu hay cuidadu ninjunu...». Pero no olvidemos que precisamente esta mezcla de ligereza y espontaneidad da gracia al texto y hace agradable la lectura de Potpourri.

En Música sentimental se podría aducir que el amplio uso del francés se justifica porque la novela se ubica en Francia y probablemente al autor quería crear ambiente con ello, porque faltan las expresiones en otros idiomas (excepción, p. 193). En Sin rumbo, Cambeceres ha conseguido una mayor concisión de expresión y usa un lenguaje más literario y metafórico, aunque nunca abandona el uso de proverbios y refranes («tiraba de la campanilla como un buey tira del yugo», «ligero como volido de perdiz) y coloquialismos («mamarracho...»). Permanecen los extranjerismos, pero ha disminuido el uso del francés (aunque sobrevive algún galicismo encubierto, como «fijar» a alguien por mirarlo). Pone en boca de los italianos del teatro el típico cocoliche, aunque no lo usa consecuentemente, por ejemplo, para la Amorini. El lenguaje de Ño Regino y Ña Felipa (cpt. 9, 32) sirve para caracterizarlos y reflejar el ambiente de la pampa y no para presentar a los personajes como «animales» curiosos (como ocurre con Taniete en Potpourri). Las frases, aunque en general todavía breves, se unen más naturalmente y no están yuxtapuestas como el staccato. Pero nunca abandonará el párrafo breve, a menudo consistente en una sola frase. Cierta libertad gramatical que está presente en toda su obra contribuye en muchos casos a lograr este estilo conciso tan típico suyo, como se pone de manifiesto en la reiterada falta del verbo: «cerca, sobre una loma, la mancha gris de una majada. Acá y allá... puntas de vacas arrojando la nota alegre de sus colores vivos». La insistencia en lo visual recuerda las pinceladas del impresionismo.

Hemos seguido la evolución que sufre la narrativa de Cambaceres desde su primera novela Potpourri hasta su obra maestra Sin rumbo. El autor ha sabido extirpar excesos como la intromisión del narrador-comentarista y sus digresiones, los apóstro-

${ }^{13}$ En la última novela En la sangre no aparecen los términos franceses que son sustituidos por el cocoliche, debido al origen social de su protagonista Genaro. Pero igual que en Sin rumbo su uso no es consecuente, puesto que en ocasiones la madre se expresa en un castellano perfecto. 
fes al lector y el tono de farsa. Con respecto a la estructura es igualmente notable el aprendizaje que se refleja en la distribución de los capítulos y las transiciones de uno a otro. Lo mismo es aplicable a la profundización psicológica y las técnicas empleadas para transmitirla al lector. Por último, en el campo estilístico, se aprecia una mayor concisión y en el lingüístico el abandono de excesivos galicismos.

Si la primera novela nos puede servir de ejemplo para un tipo de literatura característico del 80, la prosa fragmentaria de tono coloquial, la tercera Sin rumbo es el mejor representante del otro tipo: la novela técnica y estilísticamente elaborada, género que no se consolidó en la Argentina hasta la generación del 80.

\section{Bibliografía}

Adoum, Jorge Enrique, Entre Marx y una mujer desnuda: texto conpersonajes. México. Siglo Veintiuno. 1976.

Asturias, Miguel Angel, Obras escogidas, vol. 1. Madrid. Aguilar. 1964.

Cambaceres, Eugenio, Potpourri. Buenos Aires. Minerva. 1924.

Música sentimental. Buenos Aires. Minerva. 1924 con un prólogo de Arturo Giménez Pastor.

Sin rumbo. Buenos Aires. Lajouane. 1885.

En la sangre. Madrid. Editora Nacional. 1984, edición y prólogo de Claude L. Cymerman.

Cané, Miguel, «A propósito de Sin rumbo» en la edición de esta novela por Teresita Frugoni de Fritzsche. Buenos Aires. Plus Ultra. 1980, pp. 185-198.

Cymerman, Claude, Eugenio Cambaceres por él mismo. Buenos Aires. Inst. de Literatura Argentina «Ricardo Rojas». 1971.

Jitrik, Noé, El mundo del 80. Buenos Aires. CEAL. 1982.

López, Lucio V., La gran aldea. Buenos Aires. Atlántida. 1974.

Mansilla, Lucio V., Entre-nos. Causeries del jueves. Buenos Aires. Hachette. 1963.

Schade, George D., «El arte narrativo en Sin rumbo», Revista Iberoamericana, enerojunio 1978, no 102-3, pp. 17-29.

Tcachuk, Alexandra, Eugenio Cambaceres vida y obra. Ph. D. Northwestern University. 1976.

Viñas, David, De Sarmiento a Cortázar. Buenos Aires. Siglo Veinte. 1974. 
